Received: January 21, 2018

Revision received: February 2, 2018

\title{
Research on the Innovation Method of Continuing Education Model for Professional Technical Personnel in Manufacturing Industry
}

\author{
Junkai Yang ${ }^{1}$ \\ Hohai University
}

\begin{abstract}
Manufacturing industry is an important part of China's industry and plays an important role in China's economic development and industrialization process. In the face of the increasingly fierce competition, the cultivation of professional technical talents in manufacturing is particularly important. The continuing education of professional technical personnel is an important method for enterprises to cope with competition and break through the predicament. Through the literature review of the development of the manufacturing industry in the Yangtze River Delta region and the questionnaire survey of professional technical personnel, this paper discovers that the continuing education of technical personnel in region does not necessarily meet the needs of technical personnel and that the teaching mode is single. Also, corresponding innovative solutions are proposed.
\end{abstract}

\section{Keywords}

Manufacturing • Professional Technical Personnel • Continuing Education • Innovation

\footnotetext{
"This work is supported by the Social Science Foundation of Jiangsu in China (14ZXB006)

${ }^{1}$ Correspondence to: Junkai Yang (PhD), Junkai Yang, Business School, Hohai University, Nanjing 211100, China. Email: jkyang8@126.com
}

Citation: Yang, J. K. (2018). Research on the Innovation Method of Continuing Education Model for Professional Technical Personnel in Manufacturing Industry. Educational Sciences: Theory \& Practice, 18(5), 2325-2331. http://dx.doi.org/10.12738/estp.2018.5.130 
Modern society is the society of talent competition. Talents with innovativeness and strong technology commercialization ability are important forces for the development of enterprises (Harada et al., 2002). Continuing education can improve the quality of staff, not only in terms of professional skills, but also comprehensive skills in management, communication, and even language proficiency ( $\mathrm{Li}$, Zhang, \& Chai, 2010). Therefore, continuing education is valued by more and more countries and regions. According to statistics, the investment in continuing education in developed countries accounts for between $2 \%$ and $3 \%$ of GDP (Sun, 2007).

Since the introduction of continuing education in the 1970s, China has carried out a lot of related work. With the economic development, China has paid more and more attention to continuing education. The Fifth Plenary Session of the 15th CPC Central Committee asked to focus on the cultivation and use of talents (Guo, Tang, Zuo, Liu, \& Jin, 2008). However, due to the lag of the economic benefits of education, some regions do not attach enough emphasis on continuing education. In general, the foundation and existing inputs of continuing education are still relatively weak compared with other educational systems (Bathelt, Munro, \& Spigel, 2013). Through the literature review and questionnaire survey, this paper analyzes the problems existing in the implementation process of continuing education for professional technical personnel in manufacturing industry in the Yangtze River Delta region and proposes targeted innovative solutions.

\section{Research Background}

The exploration of unknown problems and the pursuit of progress are human nature (Zhou, 2013). Therefore, the continuing education has a long history. Since Industrial Revolution, continuing education has been further developed in developed countries so as to cultivate the labor force adapted to industrial production.

\section{Concept of Continuing Education}

According to the definition of UNESCO, continuing education refers to the education of adults who have been disconnected from formal education, participated in work and undertaken social responsibility. However, there are some differences in the understanding of continuing education in different countries (Corrocher, \& Cusmano, 2014), as shown in Table 1.

Table 1

The Concept of Continuing Education in Different Countries

\begin{tabular}{|c|c|}
\hline Country & Continue education \\
\hline Britian & After compulsory education, all formal and informal education except university education. \\
\hline & A wide \\
\hline & \\
\hline Germany & ication and university education. \\
\hline Russia & arry out systematic practice in school or through self-study. \\
\hline Italy & $\begin{array}{l}\text { One is a vocational course opened by companies and social organizations, and the other is a } \\
\text { variety of courses for literacy. }\end{array}$ \\
\hline
\end{tabular}

China has not yet had a clear definition of continuing education. According to the "Opinions on Further Reforming and Developing Adult Higher Education" (1992, etc.), continuing education refers to the "re- 
$\overline{\text { education of professional technical personnel and managerial personnel with college degree or above and }}$ intermediate professional title or above".

\section{Concept Differentiation}

To further clarify the concept of continuing education, it is distinguished from similar concepts:

(1) On-the-job training

On-the-job training refers to the training carried out by enterprises according to the requirements of their posts, which is an important part of continuing education to improve the ideological quality and working competence of employees.

(2) Continuing engineering education

Compared with continuing education, continuing engineering education is limited in scope, which refers to the education of on-the-job researchers and engineers (Cloudt, \& Kouvaritakis, 1987). Continuing education refers to the education of professional technical personnel to adapt to the development of science and technology.

\section{Research Methods}

In order to analyze the status quo and existing problems of continuing education for professional technical personnel in manufacturing industry in the Yangtze River Delta region, relevant research is carried out by the following methods:

(1) Literature review method. The literature and materials are collected and analyzed to understand the relevant situation in the field of continuing education for professional technical personnel at home and abroad.

(2) Statistical analysis method. Through the questionnaire survey, the status quo of continuing education for professional technical personnel in manufacturing industry in the Yangtze River Delta region is obtained and the existing problems are analyzed.

\section{Status Survey}

The healthy and sustainable development of the manufacturing industry plays an important role in the economic development in the Yangtze River Delta region. With the integration of the global economy, the competition among domestic enterprises will become more intense and the impact of foreign enterprises on domestic enterprises will be even fiercer. In order to maintain the good development of the enterprise, the continuing education of professional technical personnel is even more important.

\section{Status analysis}


Yang / Research on the Innovation Method of Continuing Education Model for...

Technical personnel refer to staff engaged in technical work in the process of engineering design, construction, and material production. The status quo of technical personnel in manufacturing industry in the Yangtze River Delta is as follows:

(1) Technical personnel know little except the knowledge in their domain and the rapid development of new technologies makes it difficult for them to cope with the dramatic changes;

(2) Compared with applied talents, the number of management and innovative talents are less;

(3) The knowledge structure of technical personnel needs to be optimized. There is a lack of comprehensive talents who understand technology, management and law.

\section{Questionnaire Survey}

In order to analyze the problems existing in the professional technical personnel in manufacturing industry in the Yangtze River Delta, the author investigated 150 enterprises and collected 192 valid questionnaires. The statistical results are as follows:

(1) Enterprises investigated

127 of the 150 enterprises investigated have established the continuing education system, accounting for $84.7 \%$. It can be seen that manufacturing enterprises in the Yangtze River Delta region attach more importance to the continuing education of professional technical personnel.

(2) Academic qualification and professional titles

For the enterprises that have established the continuing education system, the academic qualification and professional titles of professional technical personnel are analyzed, involving a total of 156 technician personnel. Professional technical personnel usually have certain cultural knowledge and this survey is mainly for practitioners with college and undergraduate degrees and the proportion is $3 \%$ of technical secondary school, $2 \%$ of high school, $27 \%$ of junior college, $65 \%$ of undergraduate and $3 \%$ of graduate students. In addition, enterprises or countries usually use professional titles to measure the professional level of professional technical personnel. The technical titles of investigated personnel are: $16 \%$ of technical personnel, $18 \%$ of assistant engineers, $58 \%$ of engineers and $8 \%$ of senior engineers.

(3) Form and content

Through the statistical analysis of the questionnaire, it is found that the training form required by the investigated personnel includes lectures, expert lecture, seminar and group discussion, as shown in Table 2.

Table 1

The Proportion of Continuing Education Method that the Respondents Hope to Develop

\begin{tabular}{lcc}
\hline Teaching method of hope & Number & Percent $(\%)$ \\
\hline Expert lecturing & 41 & $26 \%$ \\
Self-taught & 33 & $21 \%$ \\
Lecture & 26 & $17 \%$ \\
Discuss & 21 & $14 \%$ \\
Field simulation & 19 & $12 \%$ \\
Cosplay & 16 & $10 \%$ \\
\hline
\end{tabular}


Yang / Research on the Innovation Method of Continuing Education Model for...

For the content of education, most of the investigated personnel hope to implement the education on profession-related industry and management knowledge. This reflects that most professional technical personnel both want to improve their technical skills and their management capabilities.

(4) Effect evaluation

The questionnaire shows that the satisfaction level and proportion of technical personnel to continuing education are: $8 \%$ of very satisfied, $15 \%$ of satisfied, $67 \%$ of basically satisfied and $10 \%$ of dissatisfied. In addition, the results show that $71 \%$ of enterprises have conducted related tracking activities after the continuing education while the remaining $29 \%$ of enterprises have not. It can be seen that although continuing education has achieved certain results, it is necessary to adjust the teaching content, teaching method and effect tracking in order to improve the education satisfaction and effectiveness in production practice

\section{Problem Analysis and Suggestions}

\section{Existing Problems}

After literature review and questionnaire survey, the author believes that there are following problems in the continuing education of professional tunica personnel in manufacturing industry in the Yangtze River Delta region:

(1) Passive participation: Some professional technical personnel participate in continuing education training for the evaluation of professional titles or coping with related tasks, rather than to practically improve their professional or management ability. Due to the utilitarian nature, the training effect will be affected to some extent.

(2) Lack of teachers: In the implementation process of continuing education, the teachers are very important, which requires teachers to have solid theoretical foundation, be proficient in practical application and understand the relevant theoretical system of continuing education. However, when recruiting trainers, many enterprises usually resort to internal technical personnel or external college teachers, so that the trainers are either lacking in theoretical knowledge or practical experience.

(3) Curriculum setting: Professional technical personnel who participate in continuing education usually have certain knowledge base and relatively high professional quality, which puts forward higher requirements for the curriculum setting and teaching form of educational institutions. However, the survey finds that continuing education has problems such as outdated teaching method and monotonous form.

(4) Effect evaluation: The post-education tracking activities can feedback the educational effect for relevant personnel to evaluate the effect. At the same time, enterprises should provide a platform for the conversion of the knowledge and skill of trainees. However, the work in this aspect is not yet satisfactory.

\section{Discussion on Education Modes}

The development in current era is very rapid, so the economic growth depends more on the dissemination and utilization of knowledge and human beings are entering the era of knowledge-driven economy. Continuing 
Yang / Research on the Innovation Method of Continuing Education Model for...

education is an important means to improve the mastery and conversion of new knowledge for staff. This paper proposes the following suggestions based on the problems existing in the continuing education of professional technical personnel in manufacturing industry in the Yangtze River Delta region:

(1) Oriented by practical issues. The primary purpose of continuing education is to improve the ability of professional technical personnel to solve problems in the actual production process. Therefore, the problem orientation is of certain guiding role in textbook compilation, plan formulation and implementation.

(2) Formulating plans that satisfy the needs. Continuing education should be established as a closed-loop process including plan formulation, education implementation, effect evaluation, result feedback, summary and re-improvement. The knowledge level of trainees can be mastered and the purpose they want to achieve through continuing education can be understood by the in-depth analysis of their needs. A suitable education plan can be formulated and the effect evaluation and analysis of production conversion can be conducted after the continuing education to re-evaluate the education plan that is originally formulated, thus improving the effect of continuing education.

(3) Enriching the education mode. The traditional teacher-center mode is adjusted to student-centered and various forms of education such as discussion, simulation and on-site teaching are carried out. The professional technical personnel participating in continuing education are adults with certain work experience and professional ability and the purpose of learning is to apply the learned knowledge to the specific needs of enterprises. Therefore, in the process of education, the "understating" should be changed to "mastery", avoiding the mechanical infusion of theoretical knowledge.

(4) Establishing solid teaching staff. The teaching staff of full-time teachers and part-time teachers should be established. Full-time teachers are often rich in theoretical knowledge, but lack practical experience. Therefore, the full-time teachers from enterprises can make up for this drawback.

\section{Research Conclusions}

The requirements of professional technical personnel in today's society are innovative and compound talents. In order to meet the needs of the society, this paper analyzes the existing problems in the continuing education of professional technical personnel in manufacturing industry in Yangtze River Delta region and puts forward targeted suggestions by means of literature review and questionnaire survey:

(1) The existing problems include: lack of learning initiative and teaching staff; unscientific curriculum setting, single teaching mode, lack of corresponding effect evaluation method and skill conversion platform.

(2) The education should be based on practical issues and the education plan should be formulated that satisfies the needs. In the implementation process, the education mode can be enriched; the interests of the participants can be enhanced; and a solid teaching staff can be established. 


\section{References}

Bathelt, H., Munro, A. K., \& Spigel, B. (2013). Challenges of transformation: innovation, re-bundling and traditional manufacturing in canada's technology triangle. Regional Studies, 47(7), 1111-1130. http://dx.doi.org/10.1080/00343404.2011.602058

Cloudt, D. J., \& Kouvaritakis, B. (1987). Commutative controllers revisited: parallel computation, a new lease of life. International Journal of Control, 45(4), 36. http://dx.doi.org/10.1080/00207178708933812

Corrocher, N., \& Cusmano, L. (2014). The 'Kibs Engine' of regional innovation systems: Empirical evidence from European regions. Regional $\quad$ Studies, $\quad 48(7), \quad$ 1212-126. http://dx.doi.org/10.1080/00343404.2012.731045

Guo, H., Tang, G. X., Zuo, D. W., Liu, T. J., \& Jin, W. D. (2008). Study on a knowledge-reuse-based rapid product design process. Key Engineering Materials, 392, 543-550. http://dx.doi.org/10.4028/www.scientific.net/KEM.392-394.543

Harada, M., Teshigawara, M., Kai, T., Sakata, H., Watanabe, N., \& Ikeda, Y. (2002). Neutronic optimization of premoderator and reflector for decoupled hydrogen moderator in $1 \mathrm{mw}$ spallation neutron source. Journal of Nuclear Science and Technology, 39(8), 11. http://dx.doi.org/10.1080/18811248.2002.9715266

Li, B. H., Zhang, L., \& Chai, X. D. (2010). Introduction to cloud manufacturing. ZTE Communications, 8(4), 6-9.

Sun, G. H. (2007). Economic and industrial fluctuations (1986-2003): A preliminary study of correlation, features and driving forces. Social Sciences in China, 1, 50-71.

Zhou, J. (2013). Digitalization and intelligentization of manufacturing industry. Advances in Manufacturing, 1(1), 1-7. http://dx.doi.org/10.1007/s40436-013-0006-5 